\title{
Study on the Cost of Establishing Community Pharmacy in Lalitpur and the Role of Banks
}

\author{
Omi Bajracharya \\ Lecturer, KIST Medical College, Lalitpur, Nepal \\ Research-Fellow, Think Tank Foundation, Jorpati, Nepal \\ E-mail: bajracharya.omi@gmail.com \\ Kshitiz Upadhyay-Dhungel \\ Director, Research and Planning, Think Tank Foundation, Jorpati, Nepal.
}

\begin{abstract}
Background: The pharmaceutical market is the growing industry. Nepal has also a large and growing demand for drugs and pharmaceuticals: current figure shows that the size has estimated to be NRS (Nepalese Rupees) 16 billion, with domestic companies holding around 42 percent of the market share. The community pharmacy (a retail shop or medicine outlet) is a ground level unit through which the pharmacy services are provided to the consumers. Some community pharmacies supplies limited services due to the lack of investment. The role of banks is crucial during establishment and expansion of community pharmacy and services provided by them and this can be done by providing funds required by these companies.
\end{abstract}

Methodology: The convenience sampling method was used and to obtain detail information structured interview was taken. The study was divided into two parts. In first part, information related to community pharmacy, cost of establishment, running cost, source of capital, portion of capital funded by the banks, along with demographic detail was taken and analyzed. In the second part, bankers from different banks were interviewed to enrich the data related to the role of bank and the process involved in providing loan to such businesses. Data were analyzed using proper techniques and presented. Thirty seven pharmacists from community pharmacy in Lalitpur and 4 bankers from 4 different banks were interviewed.

Results: Out of 37, 29 (78.4\%) respondents were owner of the pharmacy shop and eight $(21.6 \%)$ were the staff member. The cost and expenditure in establishing and developing of a community pharmacy retail shop depends on location, size of the pharmacy, types of medicines, etc. The cost of establishment ranges from one hundred thousand to seven hundred thousand. The maximum percentage of capital spent on medicines was $82 \%$. About $24 \%$ of the respondent had taken a loan from different financial institute (including banks, finance companies, co-operatives, etc). Out of that only one had taken loan from bank. Surprisingly, most of the respondent $77.2 \%$ of the study do not know that bank provides loans in establishing and/or developing retail shop like retail pharmacy. Most of the bank gives loan as a business overdraft (OD) and interest of loan depends upon duration and amount of loan needed.

Conclusion: The location and scale of business determines the cost of establishment of a retail pharmacy. The bank has negligible role in such establishment. Many business-holders even do not know that banks provide loan for such retail business. Authors recommended that banks, and NBA and/or BPC need 
to work to create awareness about this. Banks also have to come up with certain provision to sanction loan to establish businesses and promote self-employment to contribute to the national economical growth.

Key words: Business Loan, Role of Bank, Corporate Social Responsibilities, Community Pharmacy, Self-employment

\section{INTRODUCTION AND BACKGROUND OF THE STUDY}

The pharmaceutical market is the growing industry, it has been estimated that the total turnover of pharmaceutical market will reach US\$1.3 trillion by 2020; the increase will be driven by soaring worldwide demand for medicines as the population ages, grows, and becomes more obese, and as chronic conditions and infectious diseases tied to global warming increase. Many researchers have predicted global warming and rise in greenhouse gases to have a major effect on the world's health, resulting in the spread of various communicable diseases and higher prevalence of respiratory illnesses (White et al., 2010).

Nepal has a large and growing demand for drugs and pharmaceuticals. In 1986, pharmacy market was around NRS 1 billion but the demand has significantly increased by $7 \%$ till $2000 \mathrm{AD}$. Considering previous data, preliminary estimates indicate requirements of around NRS 3 billion (1986 prices) by the year 2013 [GON, 1996]. Exact figure now shows the size has estimated at NRS 16 billion, with domestic companies holding around $42 \%$ of the market share (eKantipur, 2012, February 1).

Previously much of the demand of Nepal was supplied by India-based national and multinational companies. From the year 1986 till date it has been observed that the import of pharmaceutical products has reduced from $85 \%$ to $55 \%$ (APPON, 2012). The number of manufacturing industry has increased from 5 to 50 in just two decades. These data confirm that pharmaceutical industries is a fast growing sector in Nepal which is not only helping in improving health of the centre of population but also improving the economy of the nation.

The community pharmacy (a retail shop or medicine outlet) is a ground level unit through which the pharmacy services are provided. The pattern of distribution of medicine in Nepal is given in the Figure (1). 


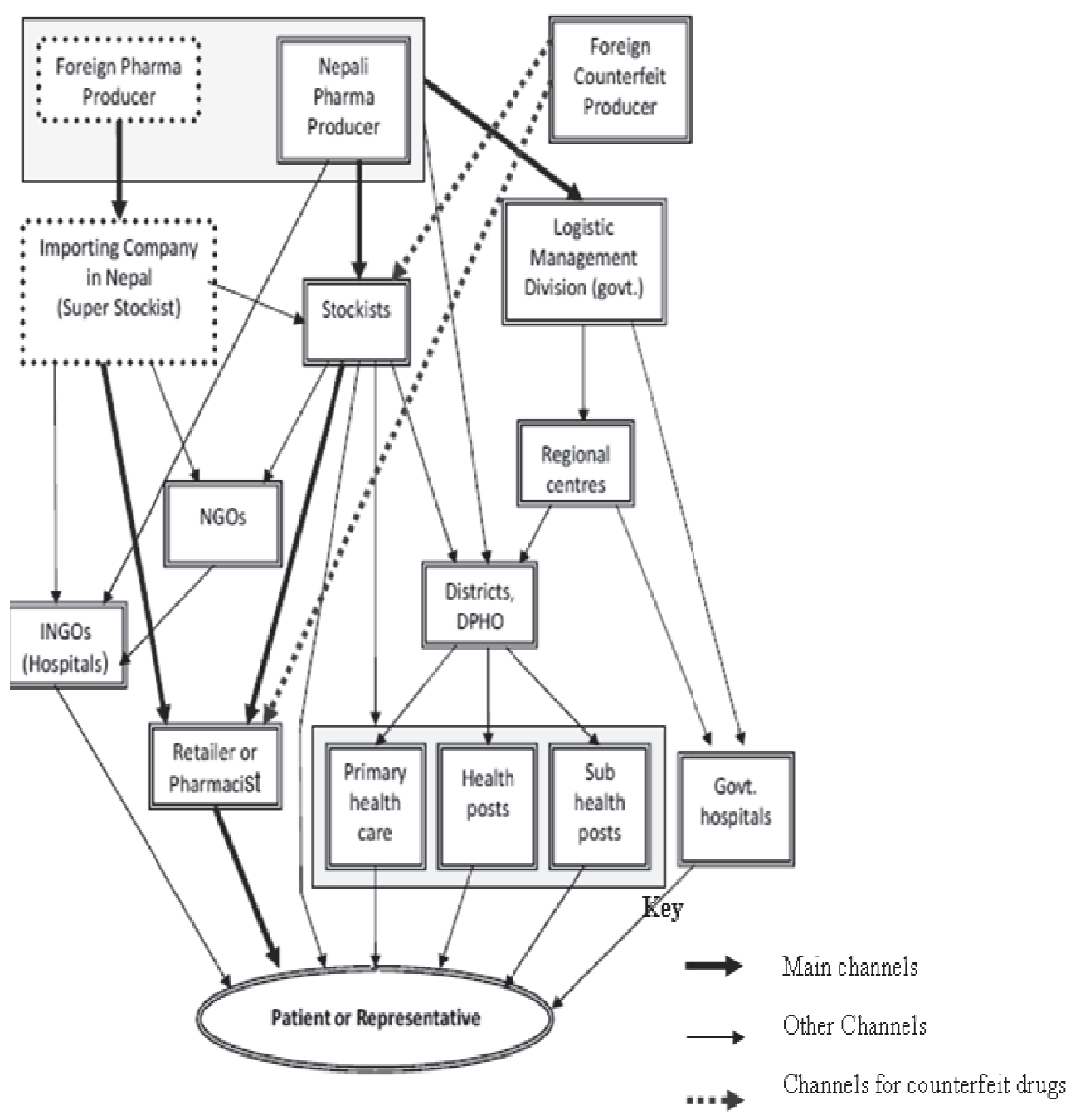

Figure 1. Pattern of distribution of Medicine in Nepal (Harper, 2007)

In order to establish a community pharmacy the retailer or the pharmacy owner should registered their pharmacy in Department of Drug Administration (DDA). DDA is the governmental organization which deals with the control and regulation of the medicines imported or manufactured in the country. It also have active role in controlling and regulation of the medicines use by the consumer.

The supply of medicine from manufacturing industry or the import of medicine to a community pharmacy therefore occurs in following sequences: Manufacturer $\rightarrow$ Super Stockiest $\rightarrow$ Stockiest $\rightarrow$ Wholesaler $\rightarrow$ Retailer. Here retailer means medicine retail shop. Community pharmacy or the pharmacy retailer plays an important role in supplying medicine to the patient or the patient representatives. The activities and growth of community product is one of the factors that determine the overall market of pharmaceutical product and industries (Bodenheimer et al., 
2002). In the scenario of rapid development of pharmaceuticals industries in global as well as Nepalese market, it is worth carrying out research on capital investment to establish community pharmacy and share of bank loan on it.

In our country community pharmacy are mostly distributed in the vicinity of the hospitals, nursing homes, polyclinics, and other health posts. Community pharmacy plays a significant role in providing health services to the local population by offering easy access to the medicine which is one of the important basic requirements of the people. Lack of access to the medicine can lead to very serious complication like under-dosing, lack of compliance, etc. In addition, some community pharmacies supplies limited services due to the lack of investment. The role of banks is crucial during establishment and expansion of community pharmacy and services provided by it (Samoly, 2004). The need of upgrading the level of existing community pharmacy service can be done by providing loans.

Study of banks' investment in establishing and developing community pharmacy could:

1. Provide information on the share of bank loan in the capital investment of the community pharmacy business;

2. Policies/criteria followed by different bank during investment in the community pharmacy;

3. Investment opportunity for bank during expansion and upgrading of the community pharmacy services.

\section{Research question}

Main purpose of the study is to find the financing source in developing or establishing pharmacy and the role of Nepalese banks in this regard. Thus following are the research questions developed for the study:

1. What are the expenses and expenditure for developing or expanding or establishing pharmacy?

2. What role has Nepalese banks played in funding these pharmacies?

3. What is the usual interest rate of the bank loan?

4. What is the potential of investment by the banks in the community pharmacy?

\section{METHODOLOGY}

Study was planned to answer the research question mentioned above. To obtain more detail information the study was divided into two parts. In first part, it includes the information related to community pharmacy, cost of establishment, running cost, source of capital, and portion of capital funded by the banks. For this community pharmacies in Lalitpur were visited and data were collected by interviewing owner and/or staff. The second part involved the interview of the bankers of Loan Department for further detail information about the role of bank and the process involve in providing loan.

\section{Sampling and data collection}

The study was conducted in Lalitpur district, Nepal and study population were owner or the staff member of the community pharmacy. The tool used to collect the primary data was schedule structured interview with the pharmacist. The 
structured interview schedule was prepared after proper literature survey and was used to collect data from the owner and/or staff of the community pharmacy to know about their establishment cost, financing, and share of capital from bank loans. The convenience sampling method was used.

All the participants were contacted personally in different places located in the Lalitpur district. Taylor and Bogdan (1998) write the basic approach of access to the private settings is the "snowball" technique. In this technique researcher start with one or a small number of people, win their trust and ask them to introduce you to other people (p.32) (as cited in Upadhyay-Dhungel, 2011).

In depth interview was taken first by visiting different community pharmacy of Lalitpur district. The average time was 30 minute for each participant in the study. They were even contacted several times as needed for clarification of confused points and verification of data. This is important for triangulation and confirmation of the facts recorded earlier as done by Upadhyay-Dhungel (2011).

After entry and analysis of data from pharmacist, the interview schedule for bankers is prepared. Again snow ball sampling (as used by Upadhyay-Dhungel, 2011) was used for data collection. A few banks were contacted and 4 bankers who cooperated in providing relevant data were interviewed. All the bankers interviewed were from the loan departments of the respective banks.

\section{Consent}

Objective of the research was explained to the respondents and their consent was taken for the participation. They were free to not to participate in the interview. The respondents were insured that their identity would not be disclosed.

\section{Data Analysis}

Quantitative data were analyzed using Excel and for the analysis of qualitative data the interactive model developed by Miles and Huberman (1994) was used which consists of the sequential steps, that is, data organizing, data reduction, data display, and data interpretation or description (as cited in Sharma, 2000).

\section{RESULT AND DISCUSSION}

The whole research result is divided into two parts: first part includes the detail about the pharmacy retail shop and responses from the pharmacist from the retail pharmacy shop about the cost of establishment and how bank have helped them in establishing and/or developing their retail pharmacy while second part includes the responses from the bankers regarding the role of Nepalese banks to establish retail pharmacy shop and provision of loans in this regard.

There are 204 registered pharmacies in Lalitpur District (DDA, Lalitpur, 2006) and 1318 in Kathmandu district (DDA, Kathmandu, 2006). The distribution of the retail pharmacy shop is comparatively more in Kathmandu valley (Lalitpur, Bhaktapur, and Kathmandu) then in other region of Nepal being the central region of Nepal and capital of the country. According to the data provided by the Department of Drug Administration (DDA) there are 204 registered pharmacies in Lalitpur district 
(DDA, Lalitpur, 2006). Thirty seven pharmacists from community pharmacy in Lalitpur were interviewed. Out of that, $29(78.4 \%)$ were owner of the pharmacy shop and $8(21.6 \%)$ were the staff member. The staff member of the pharmacy from whom the data were taken was made sure that he could response to almost all queries of structured interview. The information was verified by cross checking with other staff member of the same pharmacy retail shop. Only one person from each pharmacy was interviewed.

Out of 37 respondents, maximum number of the owner of the pharmacy retail shop were male ( 29 or $78.4 \%)$ and $8(21.6 \%)$ were female. This is in agreement with the dominating share of male population in the non-agriculture sector selfemployment (with $13.2 \%$ of the male population compared to $5.7 \%$ of female population engaged in the non-agriculture based self-employment) (CBS, 2004). Detail characteristics of the respondent are presented in Table (1). In our study, majority of samples were collected from the urban area (inside the ring road) as most of the health service facilities are located inside the urban areas. Most of the respondents were having diploma degree in pharmacy $(42.8 \%)$ and $34.3 \%$ have done orientation course about pharmacy which is usually given by DDA. Majority of the respondent were having education level below undergraduate level which shows that there is a special need for developing and upgrading the curriculum that also focuses on pharmacy business areas. It is interesting to note that almost $22 \%$ of the respondents had not registered their pharmacy shop under DDA. There is a need for adopting an effective monitoring mechanism by DDA as some respondents does not follow the legal process of registration before starting community pharmacy business.

Table 1: Characteristics of the respondent $(n=37)$

\section{Variable \\ Gender}

Male

Female

Location of pharmacy

Outside Ring-road

Inside Ring-road

\section{Education of the owner}

Anami

Orientation

Diploma

Bachelor

Master

\section{Registration information}

Frequency (\%)

Registered pharmacy under DDA

Not registered

Nearly half $(48.5 \%)$ of the respondents have expressed that the main reason behind establishment of pharmacy shop was purely for business purpose (Table 2). This is followed by $36.4 \%$ of the respondent with self-employment motive. This study indicates that there is the possibility of extending business leading by 
financial institutions in this sector if those respondents build confidence in the financial institutions for expanding their business. The education level of the self employed people varied from diploma in pharmacy to master in pharmacy. It has been found that self-employed people in urban areas (inside ring-road) are more educated than those in the semi-urban areas. Remaining nearly $15 \%$ of the respondents had mentioned social service and family business are the motive behind the opening of the pharmacy shop.

Table 2: Respondents Motive in establishing pharmacy

\begin{tabular}{lrr}
\hline Interested in opening & No. of respondent & Percentage \\
\hline Self employment & 12 & $36.4 \%$ \\
Business motive & 16 & $48.5 \%$ \\
Social services & 3 & $9.1 \%$ \\
Family business & 2 & $6.0 \%$ \\
\hline
\end{tabular}

Only $13(35.2 \%)$ community pharmacies had kept dispensing staff or the pharmacist(s) to dispense the medicine. The number of staff varied from minimum of one to the maximum of five depending on the location, their business, and the time of the owner to provide the services to their consumers of the pharmacy. Number of the pharmacy staff in the area like Lagankhel and Satdobato was high then in other area like Imadol, Hattiban, etc. The study indicates that pharmacy shop in the major urban areas generates more employment opportunities compared to the semi urban areas due to the comparatively larger concentration of number of hospitals, polyclinics, and nursing homes. A study by Goel et al. (1996) also mentioned similar differences between community pharmacy shops between urban and non-urban areas.

\section{Cost of establishing pharmacy}

Cost and expenditure in establishment of a community pharmacy retail shop depends on location (near hospital, nursing home, residential area, flow of people), size of the pharmacy, types of medicines, etc. In the study it has been found that the maximum respondents $(75.9 \%)$ have invested in the range of Nepalese Rupees two hundred thousand to six hundred thousand as the initial investment cost (Table 3 ). This shows that community pharmacy business can also be started as a small scale business without requiring massive investment.

Table 3: Showing cost of establishment (starting capital)

\begin{tabular}{lr}
\hline Establishment Cost (NRS) & No. of Respondents \\
\hline$<200000$ & 4 \\
$200000-600000$ & 22 \\
$600000-1000000$ & 3 \\
\hline
\end{tabular}

As shown in Table (4) the average initial cost was found to be NRS 408,572. The maximum and minimum investment cost found to be NRS 900,000 and NRS 110,000 . This vast difference in the investment cost could be attributed to many factors, as mentioned above. 
Table 4: Average, maximum and minimum total investment (including furniture cost) cost needed for establishment of community pharmacy by the respondents

\begin{tabular}{lr}
\hline Description & Cost in NRS \\
\hline Average Cost required for establishment of pharmacy & 408572 \\
Maximum & 900000 \\
Minimum & 110000 \\
\hline
\end{tabular}

The initial investment cost includes mainly furniture cost, medicine cost, and pharmacy registration cost. The cost of establishment includes all other expenditure like medicine cost, pharmacy registration cost, etc excluding furniture cost. The share of furniture cost in the total initial investment cost was found to be around $16 \%$. The average furniture cost was NRS 66,393 with the range of maximum value of NRS 200,000 and minimum value of even NRS 10,000 depending upon the size of pharmacy.

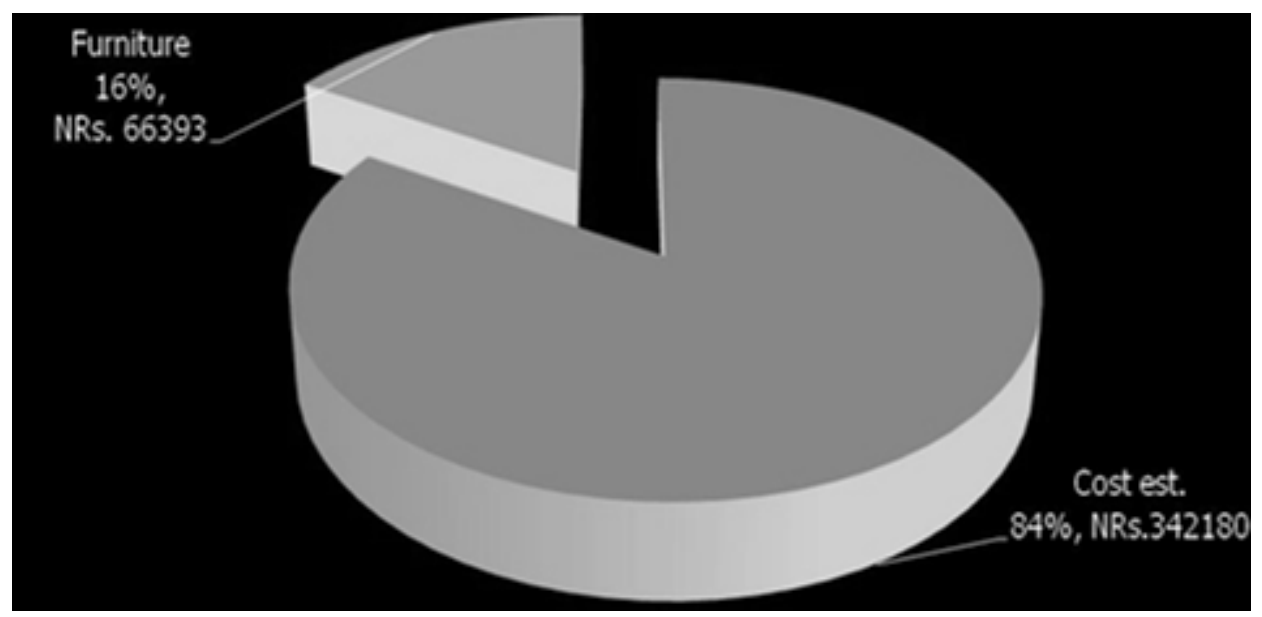

Figure 2: the distribution of initial investment on each expense head

The sources of capital amount to establish a retail community pharmacy were self earned $(44.2 \%)$, loan from financial institute $(23.5 \%)$ and loan from families $(14.7 \%)$ (Figure 3$)$. The study shows small scale community pharmacies are mostly established by own investment without the involvement of financial institutions. However, there is potential of extending investment by financial institutions for improving the quality of the service and expanding the business. In order to improve and maintain the quality of service provided by this sector to the general public, the proper standard guidelines should be developed and implemented through concerned authority. Bank and financial institutions can play an important role by lending in this sector for improving the quality of the service as well as for their own business expansion too. 


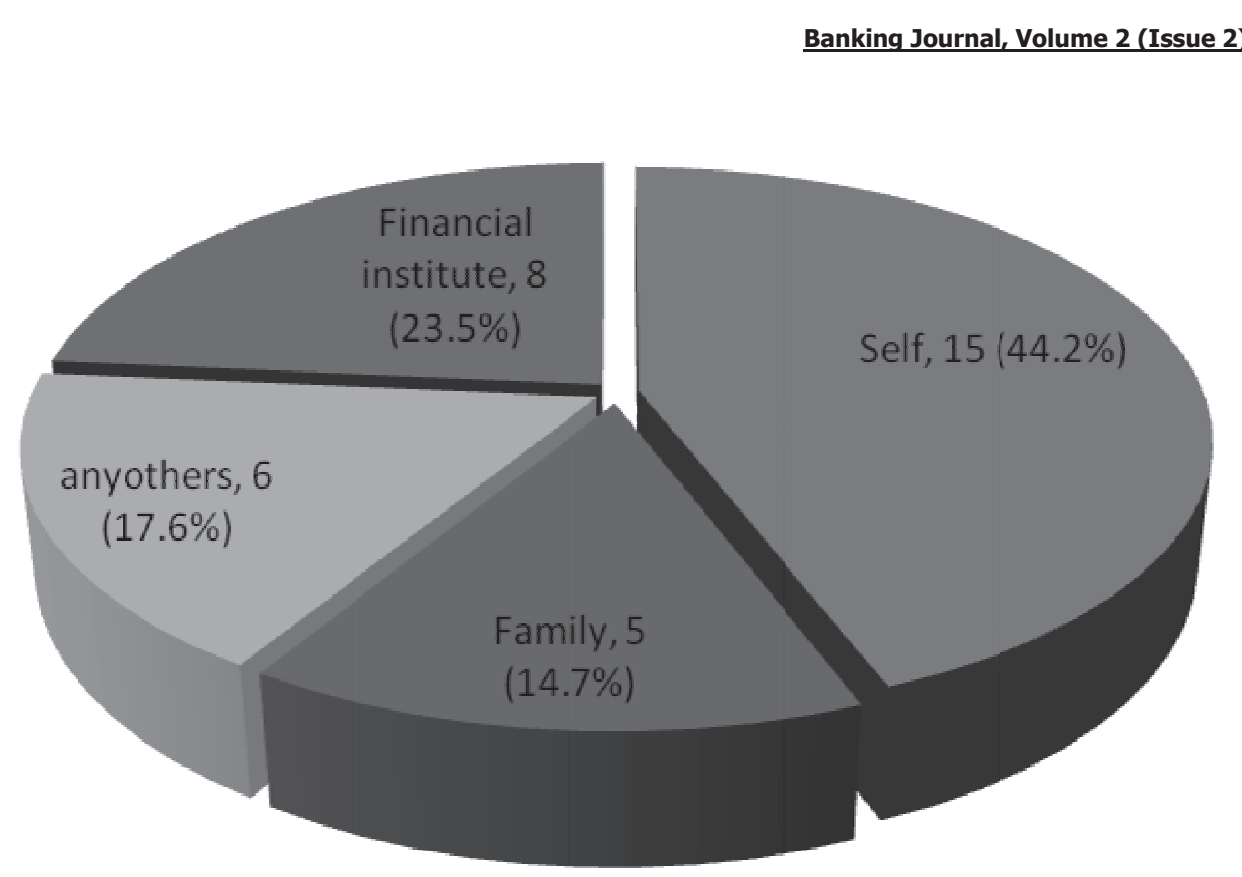

Figure 3: The sources of capital amount to establish a retail Community pharmacy

Eight of the respondent had taken loan from financial institute. Out of that four respondents had taken from finance company, three from cooperatives and only one from bank (Figure 4). This shows that bank has almost negligible role in establishing retail shops like community pharmacy and that there is high potential for business development of the banks. With proper strategies banks could penetrate this sector too and since most of the businesses are small-scale banks could help them increase their activities, which will benefit both the pharmacies as well as banks.
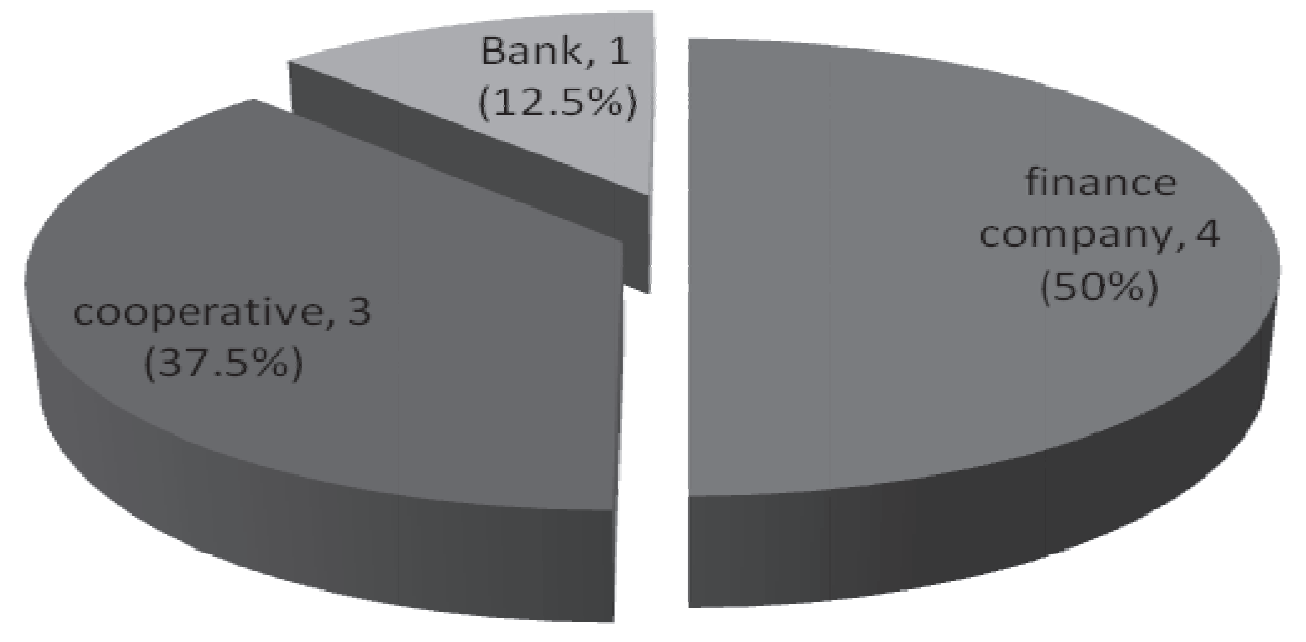

Figure 4: Loan from various financial institution 
The running cost or monthly cost of running the retail pharmacy is presented in Figure (5). The figure shows the major cost (in percentage) is incurred in running the retail business (except purchase of medicine). The maximum is spent on human resources, followed by rent. Cost of pharmacy also includes cost of registration. In order to register a community pharmacy certain amount need to be paid to the DDA and that amount depends up on the amount of capital one is investing in order to establish a community pharmacy. One of our respondents had informed that, in order to register pharmacy with a capital of five hundred thousand one have to pay NRS 1,000 to DDA for registration and the price would increase with how much amount you are investing. In order to increase the quality of service provided by community pharmacy DDA should also give emphasis on maintaining the basic standard service delivering capability by the service provider while issuing the registration certificates.

Petty

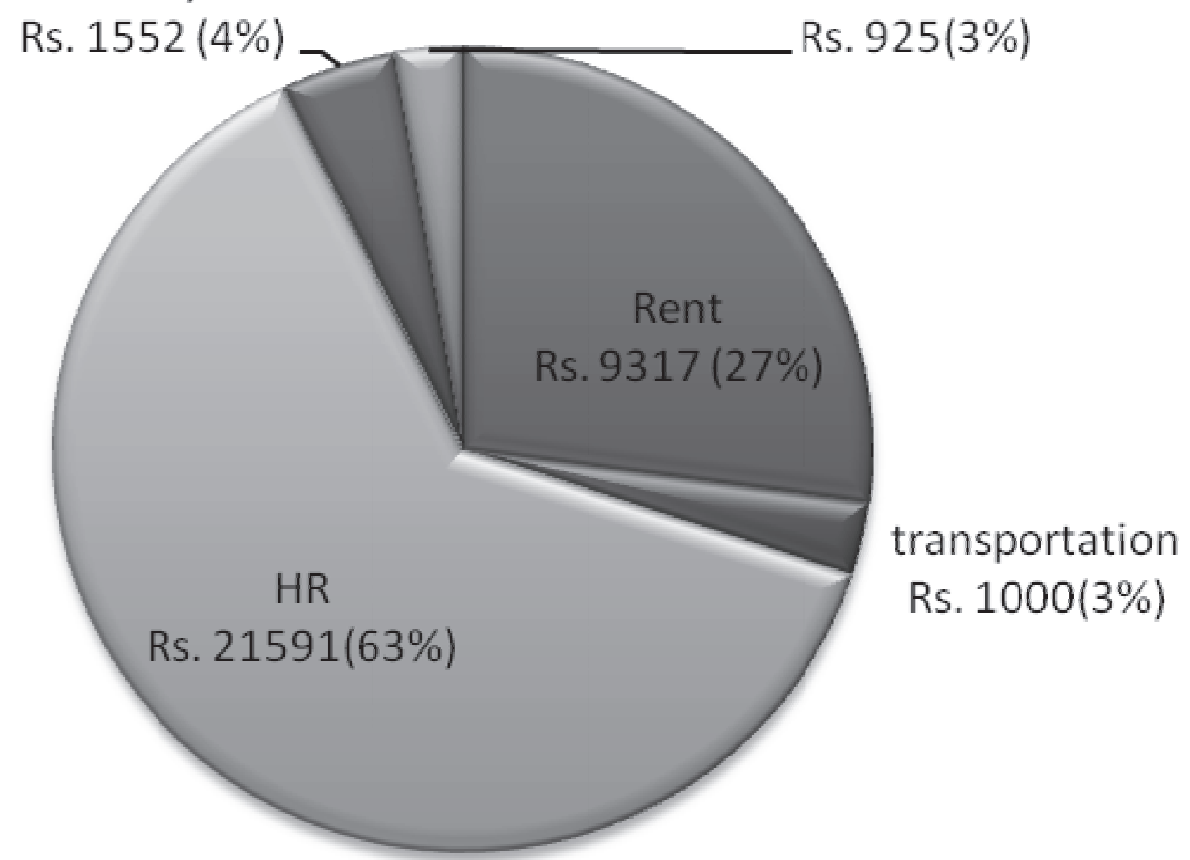

Figure 5: Detail monthly expenses of the retail pharmacy other than medicine

\section{Role of banks}

Only one respondent in our study had taken a loan from the bank, that is, from the Agriculture Development Bank Ltd. at interest rate around 15\% and 2\% service charges. Others who have taken loan from other financial institution other then bank are paying higher interest rates up to $25 \%$, which is very high. Nepal Rastra Bank (NRB), the central bank, has to look after the interest rate of such financial institutions. Banks could also play a role in this regard, by providing loans, which is usually provided at around half the interest rate charged by finance companies or cooperatives. But, surprisingly, most of the respondent $24(77.2 \%)$ of the study do 
not know that bank provides small and medium enterprises loans in establishing and/or expanding retail shop like pharmacy. And only $16.1 \%$ of the respondent said that they know about the loan facility that had been provided by the bank and remaining $6.7 \%$ had heard and knew very little about "banks giving loan".

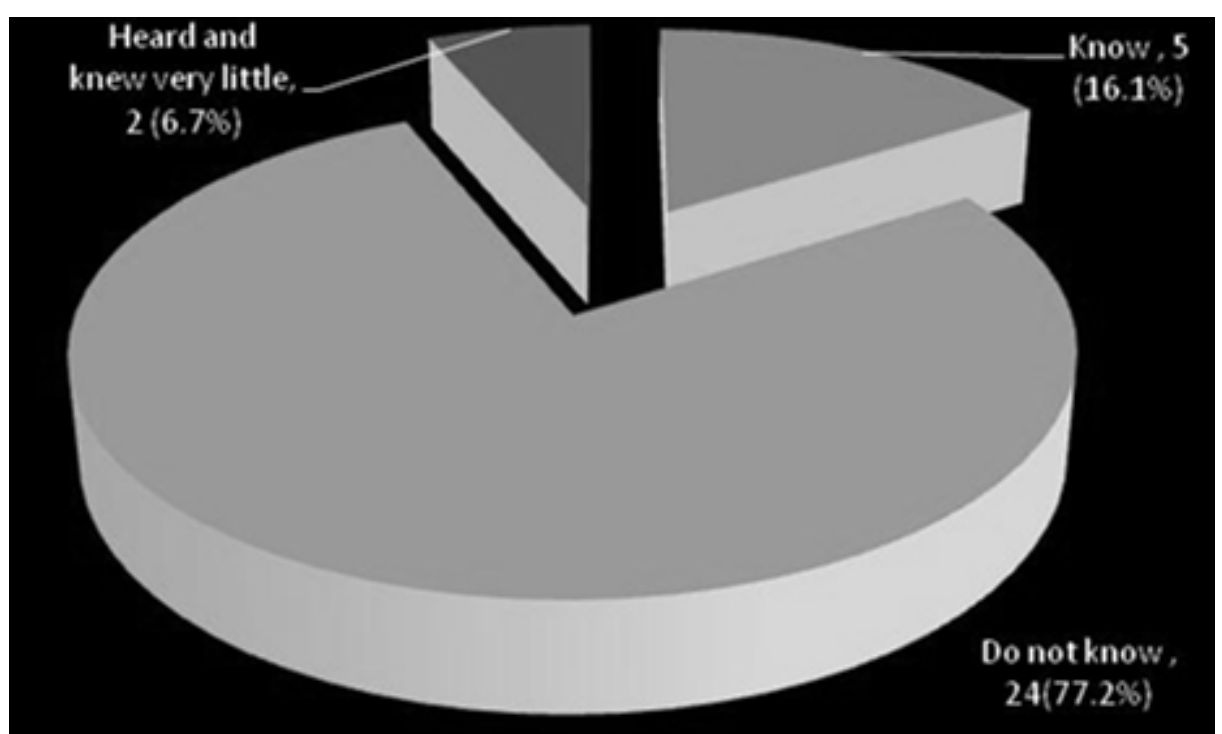

Figure 6: Respondents response to the question 'Do you know banks give loan to establish retail shop like retail pharmacies?"

Most of the bank provide loans as a business overdraft (OD) in a interest rate range of $13.5-16 \%$, depending on the duration and amount of loan with some institutions charging $1-2 \%$ service charges. The pharmacy should be registered at DDA and Department of Commerce (Banijya Bibhag) to get loan on the name of the pharmacy.

To enrich the data and information regarding role of the banks in establishing retail shop like pharmacy we interviewed personnel from 4 different banks. All of them were from (Ka-barga) A-Class banks and all were also from the loan department of their respective banks.

One of respondent (bankers) said the bank can provide either business overdraft loan or the personal overdraft loan to open the retail pharmacy. It all depends upon the personal background, education, and business experience on the same field. Loan is sanctioned against stock or collateral. If a business plan is (not ambitions but) convincing the branch manager can sanction the loan by himself/herself. S/he can forward the document including business plan (that includes the detail of business target sales receivables, profit margin, and profit projection) to the concerned authorities of his bank (for example, to DGM which will be forwarded to CEO and then to Banks' Board).

Sometimes, if a person is having a good reputation on same business (in this case pharmacy) has applied for loan or s/he may be bank's old client then on personal 
guarantee branch manager can sanctioned the loan by himself/herself. But all documentation as per need is to be presented. The document includes certificate, experience letter, license, stock, business plan, expected sale, receivables, profit margin, profit, collateral details, and so on, which depends on the individual banks. Usually the retail shop loan is of fewer amounts (4-5 hundred thousand) and to sanction that one has to enter through loan process.

As the loan amount of the retail pharmacy is less and needs lots of documentation and the procedure are lengthy and tiresome, retail pharmacy are less interested in taking loan from the banks. One of our respondents said that "if I go to bank for small amount of loan then they will take long time and lots of paperwork is needed. They may also not be cooperative if you don't know them personally. Other financial institute (finance companies, cooperatives, etc) is faster and easier than banks."

As the distributors and wholesaler provides medicine on credit too, they do not want to enter the complex loan process one of the respondent said "I purchase most of the medicine (95\%) in credit from wholesaler and go on repaying as sales goes on. I get 30-90 days to pay them back. I do not feel that I need to take loan from bank." On part of banks too, bankers seems to be less interested in sanctioning small loan for retail shop. "Smaller loan means more procedure, more files and it is not a cost and resource effective on part of bank" according to one of our respondents from the bank. This is why banks do not respond much to the customer in need of loan for small retail business. This discourages the customer to approach bank for loan for pharmacy. However, some of the commercial bank has brought the provision of business loan for retail shop and has claimed that they have made the procedure short and easy too.

Above $77 \%$ of our respondent said that they do not know that bank provide loan from the bank to open the retail shop. This is one of the areas where the banker, NBA, and BPC has to focus more seriously in disseminating the knowledge about banking and its facilities. Bank also should work along with government and other agency to address the problem of unemployment of the nation by financing the technical personnel like pharmacist to establish their own business firm. Banks are not a pure commercial organization only, they are service provider too so they also need to realize their corporate social responsibilities (CSR) (Gdansk Institute, 2003). Bank has to come up with certain provision to provide loan for qualified graduate against their certificates too. None of the bank in our context is providing loan against certificates as in several other countries (Consultative Group to Assist the Poor/The World Bank, 2006). Government and other donor agency, even NBA/BPC can work out and play role in establishing or promoting such provision in Nepalese bank. As, we are moving towards economic revolution after constitution drafting process, we should promote the educated or trained manpower to establish their own business/firm and bank is one of the organization which can be of great assets in this regard. Banks also have nothing to lose instead they will be benefitted by the expansion of their business activities by reaching the previously untapped sectors. 


\section{CONCLUSION AND RECOMMENDATION}

The cost of establishment of a retail pharmacy was studied and found that the location and scale of business determines the cost of establishment. The cost of medicine and the cost of furniture are the area where most of the capital is spent. The capital amount is managed through self-finance and loan from relatives. Very few of our respondents have taken loan from financial institutions, including banks, and out of those few only one respondent has taken loan from bank against stock. The large documentation and procedural time along with the tendency of bankers not to deal with small loan requests discouraged pharmacist to take loan. Most of the respondents do not even know that one can get loan from commercial banks to establish and expand their pharmacy/retail shop. The recent provisions of some commercial banks to promote retail business shop (SME, Small and Medium Enterprises) is seen as praiseworthy step in the development of community pharmacy sector but its effective implementation is yet to be seen.

As, we are moving towards economic revolution for uplifting the living standard of the general population after constitution drafting process, all the stakeholders should promote an enabling environment for new employment generation in the country. As community pharmacy has been seen as the promising field for selfemployment, bank and financing institutions can play an important role in promoting this sector and enrolling many educated or trained manpower.

We suggest that Banks has to come up with certain provision to sanction loan for qualified graduates and skilled workers too to establish their own business and be a part of nation economical development. The procedure and documentation should be made easy and like other countries loan also should be sanctioned against certificates without hampering the legal aspects. As per the respondents and bankers response towards the loan for retail shops or business, bankers are not considerate towards small loans. Bankers feel that more rigorous work and procedure is needed, more files are to be maintained, and it is costly to banks too. So they don't bother about small loans but a bank is not only profit making organization but also has some responsibilities towards building of nation. So they need to realize their corporate social responsibilities (CSR) too and help the government body by establishing educated and technical manpower like pharmacist by giving small loans too. By this, brain-drain can also be avoided. Government and other donor agency, as well as NBA and/or BPC can work out and play an effective role in the establishment and promotion of such provision in Nepalese banking sector. The government should bring the bankers friendly policies that encourage the bankers to invest in the community pharmacy sector. At the same time there should be effective information dissemination about the benefits of taking loan in the establishment and expansion of community pharmacy. Banks can also benefit since the untapped sector could be explored by extending the loans to this sector. Since, respondents are already taking loans at interest rates up to $25 \%$, they will be more than happy to take loans from commercial banks at lower rates, if only the procedural hassles are to be reduced. Banks, thus, have the potential for growth in this sector. 
There is a need for conjoining the policies of self-employment generation and small scale business development with the policy related to the investment in the community pharmacy sector. The educational institutions should develop and update their curriculum and train the new pharmacist as per the need and market demand.

\section{ACKNOWLEDGEMENTS}

The research is partially funded by banking promotion committee through the research grant [NBA/BPC RG\#2(B)]. The authors would like to acknowledge the technical, research, and academic support from Think-tank foundation, Jorpati, Nepal. Authors would like to thank Ms. Santoshi Thapa, student of Pharmacy for assisting in data collection. Authors also wish to thank all the participants in the study without whom this research would not have been completed.

\section{REFERENCE}

APPON. 2012. Association of Pharmaceutical Producer of Nepal. http://www.appon.org/ (Assessed on March 1, 2012).

Bodenheimer T., K. Lorig, H. Holman, and K. Grumbach. 2002. Patient selfmanagement of chronic disease in primary care. Journal of American Medical Association, Volume 288: Pp. 2469-2475.

CBS. 2004. Nepal Living Standards Survey 2003/04: Statistical Report Volume II. Central Bureau of Statistics, National Planning Commission, GON.

Consultative Group to Assist the Poor/The World Bank. 2006. Commercial Loan Agreements: A Technical Guide for Microfinance Institutions (Pp.6-10).

DDA. 2006. Registered Pharmacy List. Department of Drug Adminstration. http://www.dda.gov.np/pharmacy\%20_registration/lalitpur.pdf. (Assessed on March 9, 2012)

DDA. 2006. Registered Pharmacy List. Department of Drug Adminstration. http://www.dda.gov.np/pharmacy\%20_registration/kathmandu.pdf. (Assessed on March 9, 2012)

GON. 1996. Nepal - Foregin Investment Promotion Division. Ministry of Industry, Government of Nepal, http://www.catmando.com/gov/industry/fipd/fipd15. $\mathrm{htm}$. (Assessed on March 9, 2012.)

Ian, H., B. Petra , M. S. Subedi, and S. Bhattarai. 2007. "Drug Procurement in Nepal" working paper $1 \mathrm{~b}$, prepared for workshop on "Tracing Pharmaceuticals in South Asia", July 2-3, 2007, University of Edinburgh.

Kathmandu Post. 2012. Eight drug makers registered in first half of fiscal year. Kathmandu Post, February 1, 2012. http://www.ekantipur.com/2012/02/01 /business/eight-drug-makers-registered-in-first-half-of-fy/348232.html. (Assessed on March 9, 2012).

Goel, P., D. Ross-Degnan, P. Berman, and S. Soumerai. 1996. Retail Pharmacies in developing countries: A behavior and intervention framework. Society of Scientific Medicine, Volume 42 (8): Pp. 1155-1161.

Samoly, K. 2004. The Future of Banking in America. FDIC Banking Review, Volume 16 (2): Pp. 30-65.

Sharma, C. L. 2009. A study on the causes of educational migration in Nepal. Unpublished M. Phil. Dissertation, Kathmandu University, Lalitpur, Nepal. 
The Gdansk Institute for Market Economic. 2003. Reporting on Corporate Social Responsibility by Banks, Financial Institutions, and Listed Companies in Poland. The Gdansk Institute for Market Economic, Poland: Pp. 1-31.

Upadhyay-Dhungel K. and S. Lamichhane. 2011. Cost and Financing Higher Education by Nepalese Student in Australia: Student Loans and Role of Bank in Nepal. Banking Journal, Volume 1(1): Pp. 46-62.

White, S. J. B. 2010. Community pharmacy can deliver solutions for financing much of the healthcare reform. SA Pharmaceutical Journal, Volume 77 (6): Pp. 50-51. 


\section{APPENDIX}

\section{Questionnaire}

Place: -

Cost of establishing the community Pharmacy and role of Bank

Owners Information

Registration No:-

Gender: - Male/Female

Staff Information

Education: -

No. of Staff:

Education:-

Gender: - Male/Female

1. Why are you interested in opening a pharmacy?

2. How much amount had to be paid for registering community pharmacy?

3. Is the pharmacy registered

4. Did you have any problem in registering pharmacy? $\square$ Yes $\quad \square$ No If yes, comment:.

5. Pharmacy registered under:-

Is he /she a pharmacist:-

6. Are you a employee or owner?

7. How often does he/she stay in the pharmacy? ............ Hrs./Day
$\square$ Whole Time $\square$ Morning time
$\square$ Evening time
$\square$ Afternoon time $\square$ others

8. Do you need to renew a Lisenses one it has been registered?

9. Have you renewed your Licenses

10. Do you have to renew the licenses once it has been given?

11. How may time you have renewed it? ( Comment if needed)

12. Expense for the License registered under other person per year
$\square<5000$ $6000-10000$
$\square 10000-15000$
$\square>16000$

13. Starting Capital for the establishment of community Pharmacy
$\square<200000$
$\square$ 300000-600000 $\square 700000-1000000 \square>1000000$

14. Over all furniture cost in establishing community pharmacy .....

15. Average Monthly expenses:

Rent …........................ Transportation

Petty expense ........................... Others ......

16. How medicines are purchased?
$\square$ Cash purchase
$\square$ Credit purchase
$\square$ any other method of Purchase

Human resource

17. Source of Starting Capital
$\square$ Bank loan
$\square$ Family loan
$\square$ cooperative
Any other
$\square$ Self earned $\quad \square$ finance company

Rate of interest if it is loan other than bank:

, duration of loan EMI:

18. Do you know bank gives loan of establishing or developing community pharmacy?

19. Did you approach any Bank for financial support? $\square$ Yes

If yes, Name of the bank......

20. Reason for not approaching bank.

21. IF yes, (Bank Loan)

Did you get loan against collateral? $\square$ Yes

If yes, What type of collateral:

$\square$ Home $\quad \square$ Land

Duration of Loan

$\square<2$ years $\square$ 3-6 years

Land

$\square$ No

22. Interest $\%$ of Loan (from bank):

23. Did you have any difficulties in getting loan?.

$\square$ 7-10 years

$\square$ Shop $\quad \square$ Certificate

$\square$ Others

24. Did you have any accounts on the name of

25. Estimated sale per month:.

26. Profit percent:

27. Inspection from Department of Drug administration per year 